\title{
Violências Domésticas, Vivências e Dificuldades no Semiárido Nordestino
}

Patrícia Rosalba Salvador Moura COSTA, Universidade Federal de Sergipe José Maria Valcuende Del RÍO, Universidad Pablo de Olavide Elielma Santos MACEDO, Universidade Federal de Sergipe Leila Oliveira SILVA, Universidade Federal de Sergipe

Resumo: $\mathrm{O}$ artigo apresenta resultados sobre as características dos crimes de violências doméstica e familiar, registrados em dois municípios do Alto Sertão de Sergipe, cuja região apresenta múltiplas carências, de acesso a políticas públicas. Os dados analisados foram: inquéritos policiais; entrevista com mulheres que vivenciaram episódios de violências e profissionais da assistência social e do direito. Os resultados focam nas vivências e dificuldades enfrentadas por mulheres vítimas de violências domésticas, bem como os problemas por quais passam as/os profissionais que devem pôr em prática a defesa dos direitos das vítimas em um território distante dos grandes centros.

Palavras-Chave: Violências. Mulheres. Semiárido sergipano. Políticas públicas. 


\section{Introdução}

Há algumas décadas, nos âmbitos nacional e internacional, vêm se ampliando os aportes teóricos que problematizam as questões relativas às violências de gênero, como, por exemplo, os estudos das autoras: Mariza Corrêa (1983), Maria Gregori (1993a; 1993b; 2010), Miriam Grossi (1993; 1994; 1995; 1998a; 1998b; 1998c), Rayane Santos, Patrícia Costa, Giovanna Triñanes e Grossi (2012), Cecília Sadenberg e Grossi (2015) e Sadenberg (2018). Dentre os aspectos investigados estão, especialmente, as relações íntimas envolvidas, o tratamento institucional familiar conferido aos casos e as dificuldades que as vítimas enfrentam para acessar as instituições públicas, sobretudo, porque acontece, nesses espaços, um processo intenso e constante de revitimização.

Importantes estudos e dossiês apontam para a necessidade de pensar o problema a partir de análise interseccional e transversalizada, situando questões de raça, etnicidade, deficiência e classe social (PARENT, 2002; GROSSI; MINELLA; PORTO, 2006; SANTOS; IZUMINO, 2005; MELLO, 2017). No entanto, quando se verifica o cenário continental brasileiro, percebe-se que o tema carece de análises específicas no que diz respeito às territorialidades, especialmente, em relação às regiões rurais e interioranas do Brasil, localizadas longe dos centros de pesquisas e das instituições que ofertam serviços para mulheres em situação de violências.

Teoricamente, este texto usa como categoria analítica o gênero, para compreender as formas de violências domésticas e familiar que atingem mulheres. Quanto aos tipos de violência doméstica, o estudo em tela considera aqueles definidos e qualificados no artigo $7^{\circ}$ da Lei Maria da Penha (BRASIL, 2006). Debate-se como, ainda, os papéis de gênero são acionados para explicar/justificar as violências doméstica e familiar no Brasil ${ }^{1}$, especialmente, em cidades pequenas e médias interioranas e da zona rural.

A análise da categoria delimitada (o gênero) tem como base os pressupostos teóricos estabelecidos por Joan Scott (1986; 2005), a fim de

\footnotetext{
1 O Brasil está sob a égide de um executivo nacional fundamentado em um discurso machista, armamentista, racista e sexista, que se alastra de forma direta, mas também simbólica, em todas as instituições, afetando gerações de mulheres, assim como pessoas do grupo LGBTQI+, negros, indígenas e pobres. Respaldado nesse discurso, o governo promove o desmonte das políticas públicas de atendimento às mulheres em situação de violência.
} 
Patrícia Rosalba Salvador Moura COSTA, José Maria Valcuende Del RÍO, Elielma Santos MACEDO, Leila Oliveira SILVA.

compreender os significados culturais e as relações de poder que se estabelecem nas construções sociais em torno da diferença sexual. Segundo Judith Butler (2003), as performances usadas socialmente para se manter o status quo dominante sobre todas as formas de feminilidades, estão em profunda constituição com "os conjuntos específicos de relações, cultural e historicamente convergentes" (BUTLER, 2003, p. 29).

Os dados do Anuário de Segurança Pública Brasileiro (FÓRUM BRASILEIRO DE SEGURANÇA PÚBLICA, 2019) destacam que, em 2018, o país registrou, 263.067 casos de lesão corporal dolosa provocada por violência doméstica, em números absolutos. Trata-se de uma média de 126,2 casos por cem mil habitantes, ou seja, um registro a cada dois minutos. Os números são alarmantes. Em Sergipe, no mesmo ano, o número registrado foi de 5.121 casos, tendo, por média, a taxa de 224,8 por cem mil habitantes. Sergipe está acima da média nacional, ficando atrás apenas do Acre, do Mato Grosso, de Rondônia e do Distrito Federal.

Nos casos de feminicídio, os estudos propagam que as mulheres negras são as mais assassinadas no país. $O$ ápice da mortalidade ocorre em mulheres com 30 anos de idade. Quanto ao grau de escolaridade, aponta-se que $70.7 \%$ das mulheres possuíam apenas o Ensino Fundamental. Os algozes geralmente são os próprios companheiros ou excompanheiros. Quando se acrescentam às análises as taxas de violência sexual, o resultado revela cenários, de fato, horrendos e joga os holofotes para o dilaceramento dos corpos de mulheres, do sul ao norte do Brasil.

As/os pesquisadoras/es Parry Scott, Fernanda Nascimento, Roseneide Cordeiro, Giselle Nanes (2016) apontam que as mulheres que vivem nas cidades pequenas e nas áreas rurais encontram maiores dificuldades para acessar as políticas públicas:

Nas áreas rurais, ainda são escassos os acessos das mulheres aos equipamentos institucionais de políticas de enfrentamento da violência, seja pela inexistência de delegacias especializadas, seja pelas múltiplas dificuldades de cumprimento da Lei Maria da Penha (sobretudo por parte dos aparelhos policiais e jurídicos) ou pelas precárias condições de estruturação de redes institucionais locais (SCOTT; NASCIMENTO; CORDEIRO; NANES, 2016, p. 853).

Essa realidade contribui para que boa parte das mulheres que vivem na zona rural tenha dificuldade de denunciar seus agressores. Por outro lado, estudos realizados por Patrícia Costa, Amanda Marques e Hannah Oliveira (2016), em assentamentos rurais do semiárido de Sergipe e agreste alagoano, apontam que existe um tabu em torno dos 
posicionamentos das pessoas sobre violências de gênero em regiões rurais. Não se fala, não se denuncia, mas a maioria das pessoas conhece ou ouviu falar sobre alguma mulher em situação de violência. Nesses lugares, os papéis sociais que marcam as feminilidades e as masculinidades são definidores também das formas de silenciamentos impostos a todas as expressões do feminino.

Algumas questões podem ser acionadas para explicar tal silenciamento, dentre elas destacam-se: o medo, a impotência, a baixa estima, a ausência de políticas públicas, a dependência econômica e emocional, a presença de filhos, a cobrança social para manter o casamento. No âmbito das violências praticadas contra as mulheres, principalmente em áreas mais interiorizadas, esses tópicos estão inteiramente relacionados. Quando se trata da violência doméstica cometida por parceiros íntimos ou ex-companheiros, é fundamental considerar que as estruturas sociais, há muito, legitimam as condutas criminosas, ratificadas em atitudes culturais que passam de geração a geração.

\section{Metodologia}

$\mathrm{O}$ artigo traz à pauta resultados de pesquisa realizada em dois municípios do Alto Sertão de Sergipe ${ }^{2}$. Trabalhou-se, especificamente, com a análise de 314 inquéritos policias (IP), ao todo, registrados na delegacia de cada cidade, relacionados ao crime tipificado como violência doméstica. Uma vez que tais documentos são referentes aos anos de 2012 a 2017, foi possível definir o perfil sociológico das mulheres denunciantes, bem como os tipos de crimes. A análise desses documentos baseou-se em Costa e Nichnig (2015).

A fim de complementar a análise desses dados, realizou-se entrevista com cinco mulheres em situação de violência, com o objetivo de aprofundar quais as significações que esse tipo de ato tem na vida delas. Cabe assinalar que o acesso a essas mulheres, para que fossem efetuadas as entrevistas, consistiu em uma tarefa árdua, porque sempre estavam acompanhadas dos homens com os quais residiam. Contudo, tal obstáculo foi superado nas ocasiões em que houve privacidade das pesquisadoras com as entrevistadas, momento em que estas romperam o silêncio e se

\footnotetext{
2 Este estudo seguiu os princípios éticos das pesquisas em Ciências Humanas, garantindo, assim, a confidencialidade das informações, a privacidade dos/as participantes e a proteção de sua identidade BRASIL (2016).
} 
Patrícia Rosalba Salvador Moura COSTA, José Maria

Valcuende Del RÍO, Elielma Santos MACEDO, Leila

Oliveira SILVA.

expressaram - com gana de serem ouvidas - acerca de suas dores, seus dissabores e seus sonhos.

Por último, foram entrevistadas seis pessoas que trabalham nos serviços públicos atendendo a vítimas de casos de violência doméstica: dois servidores lotados nas duas delegacias da cidade e quatro assistentes sociais que trabalham no CREAS. A partir dessas entrevistas, foi possível compreender as formas de atendimento dispensadas às mulheres quando essas procuram as instituições. Os estudos de Roberto Cardoso de Oliveira (1998) fundamentaram os procedimentos atinentes às entrevistas.

As cidades pesquisadas localizam-se no Alto Sertão de Sergipe, na região do semiárido, são consideradas de pequeno porte por possuírem menos de 50 mil habitantes. O estado de Sergipe abrange 29 municípios incluindo todos os 7 que integram o Alto Sertão, que apresentam vulnerabilidades ambientais, institucionais e socioeconômicas. Em 2010, um dos municípios estudados tinha uma população de 32.497 pessoas e IDHM igual 0,587; o outro apresentava 30.880 habitantes, com destaque para 72,35\% que vivem na Zona Rural, e IDHM igual 0,529 (INSTITUTO DE PESQUISA ECONÔMICA APLICADA, 2020), portanto ambos são considerados municípios com baixo desenvolvimento humano. A Figura 1 apresenta a localização do Alto Sertão:

\section{Figura 1: Localização do Ato Sertão de Sergipe}
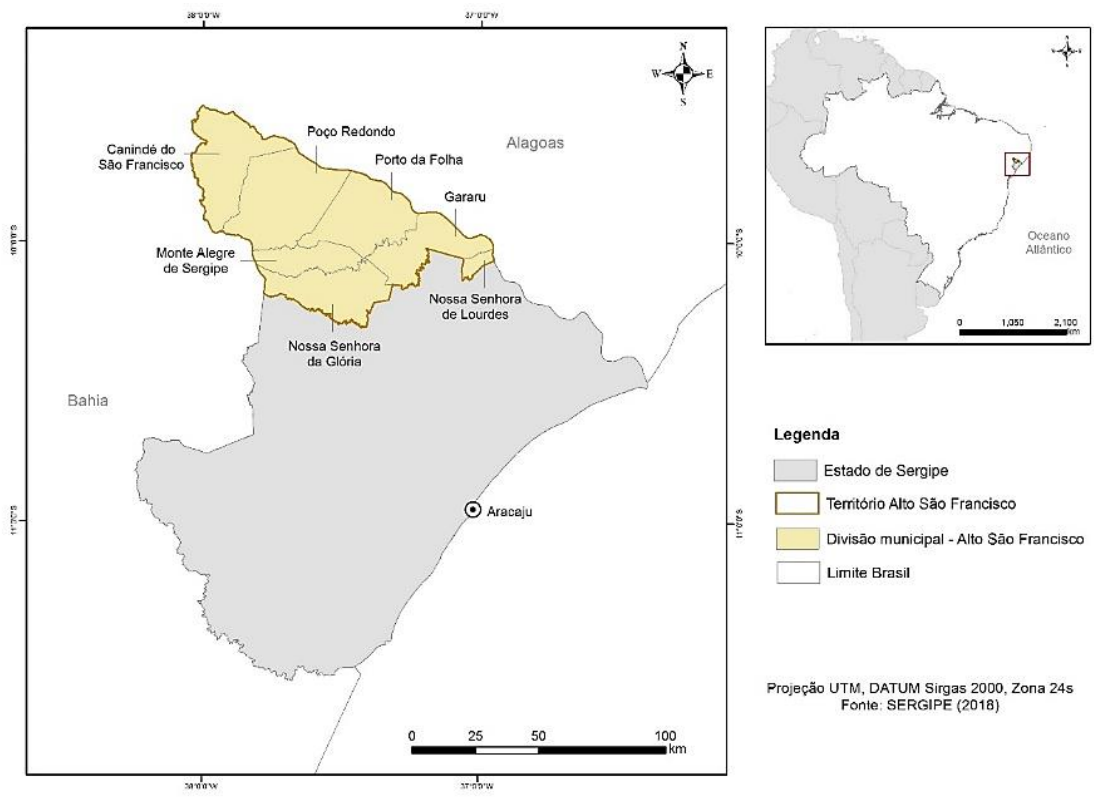

Fonte: Autoras do Estudo. 
Essas regiões são carentes do poder público no desenvolvimento de políticas que promovam a qualidade de vida dos/as cidadãos/ãs, o que afeta, especificamente, a zona rural. São espaços marcados também pelo acesso limitado às redes de informação, apoio, ensino, infraestrutura básica e demais políticas públicas que atendam às suas especificidades, tornando a vida dos/as moradores/as mais árida.

\section{Os inquéritos policiais sobre violências à mulheres}

A análise dos inquéritos policiais (IP) aponta que as mulheres em situação de violência doméstica e familiar que efetuaram registros junto às duas delegacias estudadas (uma em cada cidade) correspondem a faixas etárias bastante diversas. Dos dados coletados, $24 \%$ das vítimas tinham entre 15 e 25 anos de idade; 34\% entre 26 e 36 anos de idade; 19\% entre 37 e 47 anos de idade; $8 \%$ entre 48 e 58 anos de idade. As mulheres com idade entre 59 a 69 anos ocupam 2\% das taxas. Meninas abaixo dos 15 anos de idade ocuparam $2 \%$ do total de casos; e em $11 \%$ dos IP, a idade das vítimas não foi informada.

Em 33\% dos casos registrados, as mulheres se identificam como moradoras da zona rural, sendo 61\% da zona urbana. Mas cabe frisar que, em um dos municípios, o percentual de vítimas residentes na zona rural corresponde a 51\%. A zona de residência é uma informação que complementa as características de moradia e contém elementos importantes sobre o perfil das vítimas, como, por exemplo, o contexto social conservador e distante em que vivem e de pouco acesso às políticas públicas. As mulheres que moram na zona rural estão mais alijadas de ações do poder público e do acesso a instituições que atendem a vítimas de violências (hospitais, postos de saúde, delegacias especializadas, centros de referências), além da distância espacial que enfrentam para chegar até as delegacias que geralmente são implantadas na cidade. Cabe registrar que em $87 \%$ dos casos, o crime ocorreu na residência das vítimas.

Os dados referentes a profissão apontam que 37,26\% das vítimas se identificaram como lavradoras, ou seja, exercem, de alguma forma, atividades no campo; 10,19\% são domésticas e em 25,79\% não registrou esse tipo de informação.

Em 69\% dos casos, as vítimas possuíam filhos/as. Setenta e dois por cento dos registros mostram que a percepção de risco que as mulheres 
Patrícia Rosalba Salvador Moura COSTA, José Maria

Valcuende Del RÍO, Elielma Santos MACEDO, Leila

Oliveira SILVA.

tinham era de que poderiam serem assassinadas. Além desse, houve vítimas que assinalaram o risco de sofrer novos episódios de espancamentos, ou ser vítima de estupro, ou de perder a guarda de filho/a. No que diz respeito ao tipo de vínculo com o autor do crime, em 85,65\% dos IP, o praticante foi registrado como companheiro ou ex-companheiro (marido, ex-marido, namorado ou ex-namorado). Os demais vínculos são pai, padrasto, genro, filho, irmão. A taxa de filhos que agridem as mães é relevante, $4,45 \%$ dos casos.

Considerando o fato de que as violências domésticas e familiares são praticadas, em grande parte das ocorrências, pelos companheiros ou ex-companheiros das vítimas, importa identificar o tempo em que essas mulheres permaneceram no relacionamento abusivo (ver Tabela 1).

\section{Tabela 1: Tempo de Relacionamento entre vítimas e autores}

\begin{tabular}{ccc}
\hline Tempo de relacionamento & Ocorrência & Porcentagem \\
\hline o Meses a 1 ano & 27 & $8,59 \%$ \\
1 a 5 anos & 60 & $19,10 \%$ \\
5 a 10 anos & 52 & $16,56 \%$ \\
10 a 15 anos & 26 & $8,28 \%$ \\
15 a 20 anos & 23 & $7,32 \%$ \\
20 a 25 anos & 15 & $4,77 \%$ \\
25 a 30 anos & 5 & $1,59 \%$ \\
Mais de 30 anos & 3 & $0,95 \%$ \\
Não Informado & 72 & $22,92 \%$ \\
Não se aplica & 31 & $9,87 \%$ \\
TOTAL & 314 & $100 \%$ \\
\hline
\end{tabular}

Fonte: Elaboração da Autora com Base nos IP.

Verificou-se que a soma dos índices de relacionamentos que duraram entre 1 e 10 anos chega à taxa de 35,66\% dos casos. É importante registrar também que em relacionamentos curtos, correspondendo de menos de um mês a 1 ano de vivência, os índices registrados de 8,59\% dos casos são significativos, dentro do contexto dos dados levantados. Ou seja, as violências domésticas ocorrem em todos os espaços de tempo e atingem mulheres com graus distintos de convívio com os homens. Em relação ao 
tópico "Não se Aplica" contido no formulário, significa que o crime foi cometido por pessoa que não foi identificada, nos autos, como "companheiro" ou "ex-companheiro".

\section{Das medidas protetivas: o solicitado e o concedido}

Medidas protetivas são garantidas pela Lei $\mathrm{n}^{0} 11.340 / 2006$, também denominada Lei Maria da Penha, que cria “[...] mecanismos para coibir a violência doméstica e familiar contra a mulher". Tais medidas são de caráter preventivo, podendo impor restrições ao agressor, especialmente no que diz respeito ao limite espacial de aproximação das vítimas. Também são usadas judicialmente para encaminhar as vítimas às redes de proteção e atendimento. Até o dia 13 de maio de 2019, as medidas só poderiam ser concedidas pelo Poder Judiciário. A Lei Maria da Penha foi alterada (BRASIL, 2019), a partir de então, para autorizar, nas hipóteses que especifica, a aplicação de medida protetiva de urgência, pela autoridade judicial ou policial, e para determinar o registro da medida protetiva de urgência em banco de dados mantido pelo Conselho Nacional de Justiça.

Dados que indicam a busca das vítimas por essas medidas foram analisados, neste estudo, a partir dos IP, conforme mostra o Gráfico 1.

\section{Gráfico 1: Medidas Protetivas de Urgência}

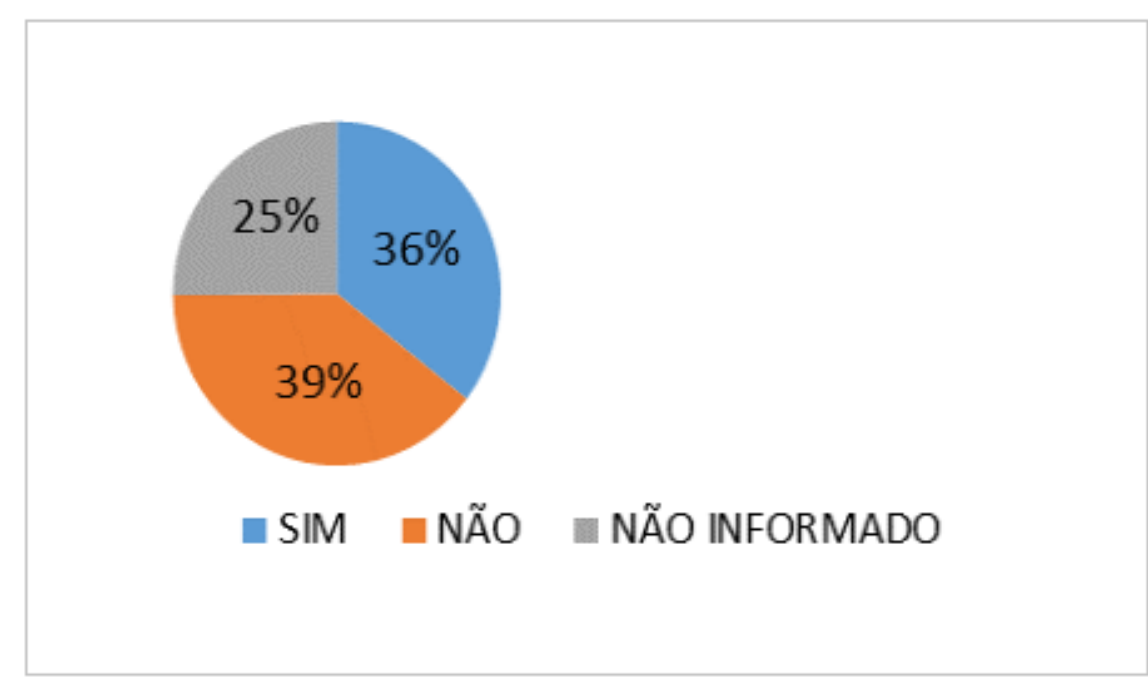

Fonte: Elaboração da Autora com Base nos IP. 
Patrícia Rosalba Salvador Moura COSTA, José Maria Valcuende Del RÍO, Elielma Santos MACEDO, Leila Oliveira SILVA.

Verificou-se que 36\% das mulheres fizeram a solicitação de medida protetiva. Em 39\% dos casos, não houve pedido. Geralmente, as vítimas realizam o pedido somente após os/as policiais que lhes atendem informarem que elas têm direito a tal dispositivo. O Gráfico 2 expõe os percentuais relacionados ao (não) atendimento às solicitações:

\section{Gráfico 2: Atendimento às solicitações de medidas protetivas}

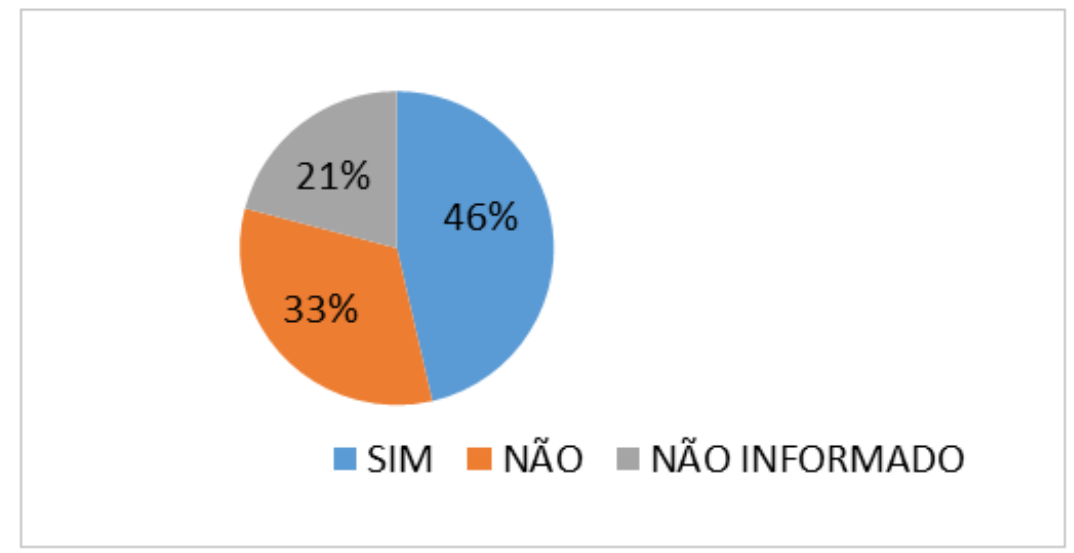

Fonte: Elaboração da Autora com Base nos IP.

Das solicitações feitas, $46 \%$ foram atendidas. É valido destacar que esse é um percentual muito baixo e pode estar vinculado à ausência, ou muitas vezes, a incompletude das informações dispostas nos inquéritos.

\section{Das redes de apoio: a necessidade do amparo social}

A leitura dos IP mostra o caminho que as mulheres em situação de violências percorrem para acessarem as redes de apoio. Nesta pesquisa, distinguimos duas instâncias que marcam essa rede e que foram mais acessadas pelas mulheres: a formal e a informal. Na primeira, encontramse instituições como delegacias, hospitais, organizações não governamentais (ONGS), Centro de Referência de Assistência Social (CRAS), casa abrigo, Conselho Tutelar e Centro Especializado de Assistência Social (CREAS). Já a segunda, pode ser entendida como uma rede de apoio formada entre parentes, vizinhos/as, amigos/as e toda e 
qualquer pessoa que se disponha a ajudar uma mulher em situação de violência doméstica.

No que diz respeito à rede formal, quando acessada, a via imediata é a delegacia, seguida da rede de saúde, geralmente, através do pedido do laudo médico pela autoridade policial, parte necessária para o processo de apuração do caso. Ou seja, a rede de saúde é acessada após a denúncia na delegacia. Esta mesma instituição encaminha a outros órgãos, comumente, o CREAS e o Conselho Tutelar, quando há crianças envolvidas. $\mathrm{O}$ acesso às redes de apoio informal é menor, talvez porque parte do registro corresponda a mulheres que moram na zona rural, e que estão mais distantes territorialmente de vizinhos e parentes a quem possam pedir socorro imediato.

\section{"Eu pensava que nunca ia ser feliz se me separasse dele"}

Enfrentar os problemas ocasionados pelo estarrecedor número de casos de violências de gênero no Brasil é uma tarefa de tamanha complexidade, especialmente, porque as políticas públicas não chegam às regiões interioranas do país, concentram-se nas capitais ou cidades de grande porte, consideradas importantes economicamente, agregadoras e centrais. No caso de Sergipe, um estado com 75 municípios, há apenas cinco delegacias especializadas para lidar com atendimento a grupos vulneráveis. Além disso, a casa abrigo e o Instituto Médico Legal também estão concentrados na capital. Diante das dificuldades encontradas, muitas mulheres desistem de encaminhar suas queixas judicialmente ou sofrem consequência psicológicas constantemente rememorando o acontecimento e esperando um desfecho para o caso, como pode ser comprovado na fala de Maria3, classe média, 27 anos, servidora pública, residente na zona urbana, onde vivenciou agressões do seu excompanheiro:

Fui agredida covardemente por um homem que conviveu comigo por um ano. No início era tudo maravilhoso, depois começaram os ciúmes, o controle do meu telefone, as brigas em público, os empurrões até o dia que me agrediu covardemente me chamando de todas as palavras vis que pode imaginar. Nesse dia, resolvi denunciar. $\mathrm{O}$ exame médico foi feito rapidamente por um plantonista no hospital regional. $\mathrm{O}$

3 Todos os nomes são fictícios, a fim de manter o anonimato. 
Patrícia Rosalba Salvador Moura COSTA, José Maria

Valcuende Del RÍO, Elielma Santos MACEDO, Leila

Oliveira SILVA.

delegado me ouviu de forma tranquila. Mas, mais de um ano depois ainda não teve a audiência judicial. Isso me causa crises de pânico, porque é uma história que não finalizou (Entrevista realizada com Maria, 2019).

A fala de Maria toca em pontos importantes, como os problemas de ordem emocional e a demora do sistema de justiça criminal para o desfecho do caso. Maria tem condições de acessar profissionais da área da psicologia e psiquiatria para se tratar, e assim o fez. No entanto, para a maior parte das mulheres entrevistadas nesta pesquisa, as assistências são deveras limitadas, muitas enfrentam suas dores de maneira crua e solitária. Quando questionada sobre a superação dos episódios vivenciados, Joana respondeu:

Não. Eu até hoje eu não superei totalmente. Eu evoluí, eu dei um passo, eu corri atrás, ainda estou correndo atrás na verdade, lutando. Mas... superar, superar tudo? O que eu tenho de lembranças aqui dentro não some assim, não se apaga assim. Então, pra eu dizer que eu superei precisa que essas lembranças não doam mais, e dói, ainda dói (Entrevista realizada com Joana, 2019).

Joana, 34 anos de idade, residente na zona rural, pertencente ao extrato popular da sociedade, expõe em sua fala toda a dificuldade encontrada para registrar o primeiro boletim de ocorrência:

No dia que eu sofri agressão física mesmo, eu passei pela delegacia não tinha delegado, não tinha escrivão, o que tinha era um policial mais ignorante do que meu marido. Então, eu voltei sem atendimento nenhum. Eu voltei sem nada (Entrevista realizada com Joana, 2019).

Em uma das delegacias havia uma profissional responsável pelo atendimento às mulheres em situação de violências, não havia sala específica para esses atendimentos. As interlocutoras apontaram que quando atendidas por ela, sentiam-se mais acolhidas.

A manutenção do silêncio e, ainda, a demora em se perceber que se encontra numa relação doentia e perigosa estão associadas à vergonha pela violência sofrida. As mulheres, às vezes, questionam-se se mereceram sofrer as violências e, nesses momentos, a baixa autoestima e demais fragilidades emocionais se exacerbam, de modo que elas demoram a procurar as autoridades ou outra forma de ajuda, seja através de amigos, seja através da família. Além disso, o fator de dependência econômica, 
sobretudo em cidades pequenas, é muito forte. Nas zonas rurais, as mulheres têm mais dificuldades para estudar e trabalhar, porque assumem muito cedo as responsabilidades domésticas, conforme destacam Costa, Marques e Oliveira (2016):

Doida, feia, assim me chamava. Ele me dizia que tinha que se conformar porque ninguém mais me queria se ele não quisesse. Doía muito. E que era melhor ficar calada porque perder ele era pior [...] eu tinha medo de voltar para casa de meus pais e também por a dependência financeira. Eu não tinha com o que comprar nada. Dependia dele para tudo [...] e isso mantém muitas mulheres à mercê de muitos homens principalmente aqui onde a taxa de desemprego é muito alta (Entrevista realizada com Joana, 2019).

Quando a gente lembra dói, né. De a gente viver assim com uma pessoa e ser judiada sem merecer, né... Se a gente merecesse seria outra coisa, mais sem merecer, dói muito, né. (Entrevista realizada com Josefa, em 2019).

Achei que tinha que fazer, obedecer, porque [...] você casou você que aguente, ah eu lhe avisei [...] medo de escutar eu te avisei [...] medo de voltar para casa de minha mãe e ouvir todo dia, eu lhe disse que casamento não era fácil agora aguente e vá viver, faça por onde viver por que agora você já se perdeu (não ser virgem) [...] aí por medo eu aguentei. Chorava e obedecia não fazia outra coisa (Entrevista com Joana, 2019).

A fala de Josefa, 30 anos de idade, moradora da zona rural, traz ao debate as formas de culpas que as mulheres em situação de violências sentem. Parece entender que, se houver um "merecimento", ainda é justificada tal atitude.

As violências sofridas e relatadas pelas mulheres são as mais variadas. A análise dos IP aponta que as violências físicas são cem por cento acompanhadas das violências psicológicas, no entanto, conforme explicam Machado e Grossi (2012), a percepção e o registro dessas violências estão condicionados à judicialização do conceito de violência psicológica. O processo de judicialização do conceito já se efetivou, mas, na prática, os registros ainda não são formalizados de fato.

É muito importante esclarecer que, nas cidades estudadas, a tipificação da violência psicológica nos autos dos IP é baixa. Na maior parte dos casos, registrou-se a violência física, no entanto, ao analisar os IPs, percebeu-se que o dano emocional é grande, afetando negativamente autoestima, uma vez que são constantemente ameaçadas, humilhadas, 
Patrícia Rosalba Salvador Moura COSTA, José Maria

Valcuende Del RÍO, Elielma Santos MACEDO, Leila

Oliveira SILVA.

ridicularizadas, vigiadas, exploradas e privadas do direito de ir e vir. Essa situação é constatada em todos os IPs investigados, assim como nos relatos obtidos nas entrevistas, de fato, significativos:

Ele me chamava de puta sempre que tava com ciúmes. Não deixava eu usar o celular. Uma vez ficou com muita raiva de mim quando estávamos numa festa, me levou embora e me empurrou do carro, saiu e puxava meus cabelos. As pessoas passavam na estrada e não faziam nada (Entrevista realizada com Maria, 2019).

Ele me tirava sangue na frente das meninas. Ele já me tirou muito sangue na frente delas. Me dava macho, me chamava de rapariga, mijava na cama e dizia que era eu que tinha transado com mais os homens... e eu dizia: para com isso pelo amor de deus que um dia eu vou te deixar, e ele nunca acreditou (Entrevista realizada com Josefa, 2019).

Você não tava trabalhando não sua vagabunda! Tinha duas colegas comigo. Aí ele me bateu. Mais ele me bateu tanto nesse dia que eu fiquei roxa, peito... aí, as meninas ligaram para polícia, aí, quando a polícia chegou, tirou ele de cima de mim. Aí, pronto. Aí, desse dia eu não morei mais com ele, aí, eu fretei um carro e vim embora, até hoje (Entrevista realizada com Cícera, 2020).

Todas essas falas mostram que as agressões são também praticadas na presença de outros indivíduos, sejam as crianças da família, transeuntes ou pessoas que mantêm relações de amizades, como afirma Cícera, de 32 anos de idade e moradora da zona rural. A demora em obter uma resposta do sistema de justiça gera incerteza, medo, desconfiança e cria a sensação de que a impunidade sustenta as violências perpetradas, além de conferir ao agressor certa segurança de que nada vai acontecer. Ao mesmo tempo, essa é uma das justificativas que faz com que as mulheres desistam de dar continuidade aos episódios denunciados:

Era para mim ter ido lá de novo para levar testemunha, aí, eu não levei, para ele ficar. Pagar, né? Para ele ficar mais um tempo na cadeia que ele só fez pagar uma cestinha básica. Ele faz a mesma coisa que eu soube que ele tentou agredir essa esposa dele, a atual esposa dele (Entrevista realizada com Cícera, 2020).

Romper com o ciclo da violência 4 não é fácil, requer da mulher coragem, porque são muitos os fatores que contribuem para a

4 Para Cunha (2007) o ciclo da violência passa por basicamente 4 fases: a) tensão; b) agressão; c) pedido de desculpa; e d) reconciliação/ lua-de-mel. 
permanência nos relacionamentos agressivos, o primeiro deles é a ausência de consciência de que está vivenciando um relacionamento abusivo e agressivo. Grossi (1998b) esclarece que, no momento em que a vítima decide fazer a denúncia, ela deseja de fato acabar com as agressões sofridas, mas não necessariamente, romper com a relação. Por outro lado, segundo a autora, a ausência da denúncia ratifica o silêncio e contribui para que o agressor continue a violar as normas de convivência e negociação do relacionamento. Os relatos de Joana e Cícera são exemplos das dificuldades que as vítimas sentem em reconhecer rapidamente que vivenciam relacionamentos violentos, além disso, elas têm a esperança de que 0 agressor se arrependa e mude suas atitudes:

As agressões começaram assim que eu fui morar com ele, mas para eu perceber já tinha muito tempo, foi quando eu me dei conta que eu não estava mais vivendo, eu estava vegetando. A primeira proibição foi a roupa, para depois vir todo o resto de proibição. (Entrevista realizada com Joana, 2019).

Ele me batia num dia e no outro ele estava de joelho nos meus pés dizendo que estava arrependido, depois continuava fazendo as mesmas coisas ou pior... ele era daquele homem que ele aprontava e no outro dia ele lhe comprava com presentes, dinheiro, passeio, carinho que ele era muito carinhoso agora tinha a fase agressiva, era violento ai não adianta você viver com uma pessoas dessa, né [...] aí, eu me separei dele, passei dois meses... aí, ele veio e pediu pra mim voltar que não ia acontecer isso, não ia mais me agredir. Aí, eu voltei ... passei mais dois meses com ele... aí um dia ele só bebendo, bebendo [...] aí, ele não contou história me deu um tapa, eu estava até na cozinha, aí a cozinha era de cerâmica... aí, eu deslizei do tapa que ele me deu, aí, quando ele me deu o tapa, eu olhei para cima da minha geladeira, aí, olhei uma faca, aí, eu peguei a faca, quando eu peguei a faca eu dei nele, aí, nós saiu os dois no meio da rua com a menina toda lavada de sangue. Já sofri muito. Aí, na terceira vez eu fiz um juramento para mim, eu disse: no dia que eu apanhar dele [e] que eu não merecer, eu deixo ele (Entrevista realizada com Cícera, 2020).

A demora em denunciar está também vinculada aos afetos constituídos nas relações:

É muito difícil e a situação é complicada quando se envolve seus sentimentos, sentimentos de outros, e principalmente quando se têm filhos. No dia que você ver seus filhos gritando ai, ai, pare, pare, pare, não é fácil e aí você ter que reagir, é muito difícil. É por isso que muitos 
Patrícia Rosalba Salvador Moura COSTA, José Maria

Valcuende Del RÍO, Elielma Santos MACEDO, Leila

Oliveira SILVA.

se calam, mas a gente tem que se reerguer, pensar que tudo passa, e fazer por onde. Porque se eu não tivesse tomado a decisão de ditar as minhas regras até hoje o controle era total (Entrevista realizada com Joana, 2019).

A tomada da decisão de fazer a denúncia gera incertezas quanto ao futuro da família, dos filhos e da própria percepção/questionamento da felicidade na constituição de outro relacionamento:

Eu pensava que eu nunca ia ser feliz e seu me separasse dele, eu não ia arrumar outro homem, que outro homem não ia olhar para mim, e é uma ilusão, né? Isso é uma ilusão. Eu pensava comigo: ah, se eu deixar ele ninguém vai me querer, eu não vou arrumar outro, eu não vou ser feliz [...] e hoje eu sou feliz, graças a Deus (Entrevista realizada com Cícera em 2020).

A fala de algumas mulheres revela que, ao conseguir sair do relacionamento agressivo, as percepções sobre as experiências vivenciadas lhes conferem maior criticidade sobre os papéis de gênero, a liberdade sobre o corpo e o poder de decidir e continuar a viver, considerando, sobretudo, suas vontades e seus desejos, como pontuou Joana:

Em várias situações, mas, principalmente, quando eu questionava porque que ele podia tudo e eu não podia nada. Eu não podia sair. Eu não podia me cuidar. Eu não podia viver! A não ser lavar, cozinhar, cuidar de dentro da casa, e ele podia tudo. Você pode muito bem ser uma boa esposa, você pode ser uma boa companheira, e você pode fazer o que você gosta, você pode usar o que você gosta, você pode ter o seu trabalho, se você conseguir, né? Por aqui é difícil. Mas, se você lutar e conseguir você pode ter tudo isso, ser mãe, ser mulher, ser esposa. Sendo do seu jeito, sendo do seu gosto. Basta a pessoa que esteja com você entenda que existe. Se você tem sua vida, se Deus deu a cada um uma vida, então a sua vida você é quem faz as regras, você é que tem que dizer se vai querer aquilo ou não (Entrevista realizada com Joana, em 2019).

Refletir sobre as violências domésticas em contextos interioranos chama a atenção para alguns pontos importantes que podem potencializar a permanência de mulheres em relacionamentos agressivos. Um desses é, sem dúvida, a ausência de espaços adequados para o acolhimento de mulheres em situação de violências. Nas pequenas e médias cidades do interior de Sergipe, a principal porta de entrada à rede de proteção é a 
delegacia de polícia civil, ou através dos agentes da polícia militar, em casos de flagrantes delitos.

Quando não há pessoal preparado e sensível às questões de gênero para atuar no devido acolhimento, além de espaço propícios ao atendimento, a possibilidade de a vítima desistir do prosseguimento da investigação se torna real. Além disso, instituições como Instituto Médico Legal ou casa abrigo estão localizados na capital do estado, fato que fragiliza o apoio rápido às mulheres, quando a situação o demanda. Destaca-se que o exame de corpo de delito, exigido pelo delegado para compor os autos do IP, é realizado nos hospitais regionais ou em Unidades Básicas de Saúdes, por médicos plantonistas que registram, de forma geral e sem detalhes, as marcas das agressões físicas no corpo das vítimas, o que fragiliza a composição das provas nos autos processuais, porque minimiza, muitas vezes, as violências físicas.

Outro ponto a ser destacado é a demora da mulher em se perceber na relação violenta. Os sentimentos de afeto entre o casal e a negociação das regras do relacionamento ajudam a confundir a percepção de vivências em situações de violências, especialmente porque as primeiras agressões localizam-se na esfera da violência psicológica, causando danos emocional e diminuição da autoestima (GROSSI, 1998b). O ciúme, conforme destacam Claudiene Santos e Lynna Unger (2015), transformase em precursor de todas as formas de violências que a vítima passa a vivenciar dentro do relacionamento, além de contribuir para a construção de um imaginário machista e naturalizado que constitui as relações afetivo-conjugais.

Na região do semiárido de Sergipe, a dependência financeira apresenta-se como um fator preponderante. Precisa-se observar que, nas cidades estudadas, parte significativa dos registros dos IPs são de mulheres que vivem na e da zona rural. São pequenas agricultoras que sobrevivem numa região árida, com escassez de água e dificuldade de acesso aos instrumentos urbanos. Para essas, a situação ainda é mais penosa, pois o acesso a empregos formais e à renda é mais difícil. Quando vivem na zona rural, elas participam de todo processo de produção de frutas, verduras, grãos, leite e laticínios, no entanto, a venda desses produtos fica, muitas vezes, a cargo dos companheiros, o que dificulta o acesso ao dinheiro referente à venda da produção. O Bolsa Família é, nesses casos, um programa essencial que confere autonomia às mulheres, uma vez que uma das exigências para cadastramento no programa é a titularidade ser conferida às mulheres (REGO; PINZANI, 2013). 
Patrícia Rosalba Salvador Moura COSTA, José Maria Valcuende Del RÍO, Elielma Santos MACEDO, Leila Oliveira SILVA.

As entrevistas destacaram também as dificuldades que as mulheres têm para sair do ciclo de violência. Elas estão sempre esperando uma mudança de comportamento por parte dos seus companheiros, até porque possuem filhos e têm medo, vergonha e receio de deixar a relação. $\mathrm{O}$ medo e a vergonha dialogam diretamente com a dependência financeira, a baixa estima e a falta de apoio da família. No entanto, quando as mulheres em situação de violências conseguem se libertar da relação, percebem que podem continuar a sonhar com outras experiências que lhes tragam felicidade.

\section{Como pensam e agem os/as profissionais da assistência social e do direito?}

Em cidades interioranas, o Centro de Referência Especializado de Assistência Social (CREAS) e o Centro de Referência de Assistência Social (CRAS) são instituições que ganham notoriedade entre a população mais carente, por consequência, recebem uma demanda alta. As profissionais que foram entrevistadas nos dois municípios enfatizaram que lidam com distintas violações de direitos, e esse fator dificulta o atendimento especializado às mulheres em situação de violências.

A gente sabe que o trabalho da assistência, principalmente no CREAS, se tratando de violação, né, a gente tem que ser muito humana e muito profissional. Porque você tem que trabalhar os dois, ter a sensibilidade e ser profissional. E saber agilizar a situação, buscar uma saída para a situação de violação em que o usuário de encontra (Entrevista com Profissional da Assistência Social, em 2019).

O acesso à saúde é um dos pontos frágeis nos interiores brasileiros. Isso dificulta o atendimento às necessidades das mulheres que sofrem violências. Por outro lado, os profissionais da assistência social também relatam a demora da emissão da Medida Protetiva por parte do poder judiciário. Percebem-se, portanto, dois estrangulamentos que interferem diretamente no acesso aos direitos básicos das mulheres: saúde e justiça.

A partir do momento que a gente percebe esse trauma dessas mulheres a gente encaminha para a saúde, mas a maioria das vezes o profissional para atender não está [...]. Outra questão também que a gente sente dificuldade é a questão da Medida Protetiva que demora muito aqui e tem alguns casos que o agressor chega a fazer alguma coisa contra a 
vida dessas vítimas porque eles demoram muito a proteger elas (Entrevista com Profissional da Assistência Social, em 2019).

Um ponto importante para a saída do ciclo da violência seria a implementação de políticas públicas que possibilitem às mulheres acesso à renda, o que lhe garantiria liberdade econômica e decisão sobre sua vida:

Seria necessário que fosse ampliada a rede de proteção e possibilidade para que essa mulher possa se empoderar, para que ela cresça profissionalmente, para dar uma oportunidade a mais de ela ter o seu sustento e não depender do marido ou companheiro (Entrevista com profissional da Assistência Social, em 2020).

No entanto, um ponto destacado pelas profissionais é a dificuldade para acessar as mulheres em situação de violências, tanto por demanda espontânea quanto por demandas de outras instituições, como fórum, delegacia e hospital. Isso ocorre, principalmente, porque as mulheres revelam-se com medo, vergonha, desamparo e, por muitas vezes, continuarem o vínculo com o agressor.

Falar dessa problemática no Brasil é difícil, né, porque a gente conhece todas as leis a gente sabe de tudo que está aí protegendo a mulher, mas eu acho que o maior problema ainda é o preconceito que as pessoas têm com essas mulheres. Não buscam entender o porquê. Porque muitas das vezes [...] o que mais a gente vê é [...]: "ah, ela apanhou e continua", "ah, ele agride e ela está lá”... então é o preconceito. Eu acho que não avança mais pela questão do preconceito mesmo. Porque as leis estão aí, a gente sabe que elas existem, mas, na maioria das vezes, as mulheres deixam de buscar seus direitos por medo de como a sociedade vai receber... então isso atrapalha muito (Entrevista com Profissional da Assistência Social, em 2020).

De acordo com as profissionais, as mulheres que são atendidas no CREAS têm características bastante comuns, em especial, ao quesito vulnerabilidade social e problemas familiares:

Essas são as causas maiores da violência doméstica, o perfil delas é esse. Até a evasão escolar, saem de casa cedo, casam cedo, para sair daquela pobreza, daquela vulnerabilidade social e, levando a evasão escolar deixam de ir para a escola, então aí, não tem um bom emprego, então continua naquele quadro vicioso de violência (Entrevista com Profissional da Assistência Social, em 2020). 
Outro assunto abordado durante as entrevistas foi a questão de gênero e seus avanços e retrocessos no Brasil. As dimensões dos papéis de gênero foram apontadas como preponderantes na região, especialmente $o$ aprendizado referente ao comportamento ideal para o homem e mulher, colocando, então, esses sujeitos em duas posições completamente distantes e desiguais:

É forte essa questão com relação ao gênero aqui na nossa localidade, porque as crianças já são ensinadas desde pequenas que meninas usam rosa e meninos usam azul5 e é difícil quebrar essa ideia, porque já crescem com essa ideia que os pais passam, até porque quando eles saem dessa linha que os pais estão direcionando que menina veste rosa, eles são taxados. Os adolescentes são taxados, sofrem bullying também com relação a isso (Entrevista com Profissional da Assistência Social, em 2019).

Os/as profissionais também destacam o compromisso e a preocupação em trabalhar com os agressores, conscientizando-os sobre as consequências de violarem a lei e agredirem uma mulher. Acreditam que com o desenvolvimento de atividades de conscientização em comunidades, escolas e rádios com foco principal no público masculino, apontando que a violência contra mulheres precisa ser eliminada, é possível obter algum progresso:

Então, é uma trava árdua, visto que, a nossa sociedade ela é bastante machista. É uma sociedade machista não tem para onde correr. Essa problemática acredito que tem de ser combatida direto com os agressores e, principalmente, com crianças nas escolas, nos lares mesmo com os pais [...] (Entrevista com Profissional da Assistência Social da cidade, em 2019).

Entre os profissionais que trabalham nas delegacias, a percepção sobre as violências que atingem mulheres abarca questões que envolve o político, o jurídico e o estrutural. A delegacia se constitui como uma das instituições mais importantes para as mulheres em situação de violências, em cidades interioranas. Da mesma forma, o maior número de registro de casos é o crime de violência doméstica, conforme relatam os nossos interlocutores:

5 A interlocutora usa uma frase que ficou bastante conhecida por ser dita pela ministra da Mulher, Família e Direitos Humanos do Brasil, no dia de sua posse em, 2 de janeiro de 2019. 
A violência doméstica hoje ela é o carro chefe da delegacia. Ela supera os furtos, roubos e homicídios. Supera os crimes de trânsito, enfim a maior demanda hoje da nossa cidade é violência doméstica, infelizmente (Entrevista com profissional do Direito, em 2020).

Se a delegacia fosse uma delegacia da mulher, ela teria trabalho todos os dias, estaria de portas abertas com equipe de plantão, equipe de cartório atendendo o pessoal, porque a demanda de violência doméstica é imensa (Entrevista com profissional do Direito, em 2019).

\section{Quando questionado sobre o perfil das mulheres que procuram a delegacia, um dos interlocutores relatou:}

A gente observa que a violência doméstica ela é mais camuflada nas classes mais altas. Nas classes mais baixas não, as mulheres elas vão à esmo e fazem a denúncia, elas nos procuram mais até porque elas são clientes da rede de proteção social maior, elas estão mais ligadas ao CRAS, ao CREAS, à coordenadoria das mulheres então elas têm esse apoio direto das outras profissionais. As mulheres da alta sociedade elas não, elas estão sozinhas ali, elas têm que decidir, têm que passar por vários fatores, principalmente, o econômico, e, talvez, até a dependência psicológica do companheiro, dos filhos, daquela imagem que a família tem perante a sociedade, então realmente ela tem que passar por cima de vários obstáculos, então ela é mais camuflada nas classes mais altas. Ela prefere, às vezes, procurar o psicólogo e só vai procurar a delegacia quando está naquela situação extrema de quase beirando o feminicídio (Entrevista com Profissional do Direito, em 2020).

As dificuldades apresentadas para o atendimento às demandas das mulheres são distintas. Em um dos municípios, a carência em relação ao acolhimento e à rede de apoio é apontada como maior. No entanto, a falta de estrutura física para o atendimento faz parte das duas instituições:

Não tem abrigo, psicólogo... [...] quantas e quantas mulheres chegam aqui espancadas, mulheres chegam a desmaiar aqui dentro, né... porque chegou aqui tão fora de si e quando começa a relatar o que foi que aconteceu ela cai... e você fica e agora o que fazer? O que fazer, o que fazer, o que fazer [...] O que nós fazemos aqui é tentar dar um atendimento digno a mulher. Sabemos que o local não é ideal, não é ideal. Nós não temos atendimento aqui digno para receber uma mulher que chega aqui. Ela chega aqui debilitada física e emocionalmente, chega casos aqui que a gente não sabe nem como tratar a mulher, agora, nós procuramos ao máximo dentro da real situação que nós temos aqui pelo menos dar um atendimento digno a essa mulher [...] O Ministério Público é quem nos cobra, o Ministério Público é quem, quando toma 


\section{Patrícia Rosalba Salvador Moura COSTA, José Maria Valcuende Del RÍO, Elielma Santos MACEDO, Leila Oliveira SILVA.}

ciência cobra a providencia que a delegacia tomou, mas, uma instituição de apoio a mulher, acolhimento, aqui no município não tem (Entrevista com profissional do Direito, em 2019).

Então, o maior entrave realmente é a falta de estrutura, isso deixa a função assim um pouco engessada, então falta o número ideal de servidores, de policiais, de servidores administrativos, falta também estrutura física nas delegacias, só pra se ter uma ideia a delegacia foi construída em 1988 é a mesma estrutura, por exemplo, uma sala só específica para atendimento dos grupos vulneráveis que seria as mulheres, os adolescentes, os idosos, então o maior entrave realmente é esse, é a falta de estrutura como um todo (Entrevista com profissional do Direito, em 2020).

A lentidão do sistema para emissão de medidas protetivas também é destacada como um entrave na solução dos problemas, pois deixa a vítima em situação de insegurança. Além do mais, quando são estabelecidos prazos de validade, o agressor espera que esse prazo acabe para voltar a importunar a vítima. Portanto, entende-se que o agressor se sente impune e livre para voltar a agredir, uma vez que aquilo que ele mais temia, que é a prisão e o aumento de pena, já não ocorrerá, pois acabou o prazo de validade das medidas que lhe haviam sido impostas:

Aí, ela solicita e nós fazemos o pedido das medidas protetivas, encaminhamos ao judiciário, á é que surge a dificuldade. O agressor iria, quando ele é chamado, para tomar ciência das medidas protetivas que está sendo impostas já se passaram quinze dias, dez dias do oferecimento da denúncia e até lá? [...] e outra coisa, que também, essas medias protetivas, muitas vezes, têm validade de dias, trinta dias, sessenta dias, noventa dias. Nós já tivemos casos aqui do cara contar, quando completou sessenta dias, ele voltou a importunar a mulher [...] (Entrevista com profissional do Direito, em 2019).

As relações desiguais de gênero são percebidas como um dos fatores pelos quais a violência ocorre. A cultura machista é acionada pelos profissionais do direito para explicar os altos índices de violência doméstica no Brasil:

A violência contra mulher no Brasil ela é uma epidemia, realmente é um fato lamentável porque nós fomos criados numa cultura machista em que a mulher ela é tida como um objeto. Graças a Deus, isso tem mudado. No entanto, essa cultura ainda sobrevive, sobretudo no interior do estado onde os homens ainda veem a mulher como um objeto mesmo, como só uma dona de casa, mãe dos seus filhos, e ele manda e desmanda o tanto que quer e a mulher ela é vítima justamente 
desta visão masculina e aí acaba desaguando na violência doméstica que hoje é uma epidemia (Entrevista com profissional do Direito, em 2020).

Um dos profissionais do Direito, quando questionado sobre qual o melhor investimento para reduzir os índices de violências, ressaltou:

Investir mais tanto na polícia, na rede de proteção, investir mais para acolher a mulher e criar programas, acredito eu, de prevenção. Se criar uma matéria aí na escola também em relação à violência que englobasse aí essa parte de direitos humanos, para os meninos serem criados e desde novo e percebendo que a mulher é um ser humano igual a ele, que não é inferior e que tem que caminhar lado a lado (Entrevista com profissional do Direito, em 2020).

Por fim, cabe salientar que, conforme destacam os/as interlocutores/as, as dificuldades encontradas para o desenvolvimento dos trabalhos nos dois municípios são sustentadas, sobretudo, pela falta de equipamentos necessários para o acolhimento e o encaminhamento das mulheres em situação de violências à rede de proteção. Parece haver uma sensibilização por parte dos/as profissionais entrevistados/as em relação ao tema, mas, embora seja um fato importante, as mulheres necessitam acessar políticas públicas que lhes garantam permanecer vivas e sadias tanto física, como psicologicamente. Os casos, em municípios do interior, parecem ficar mais distantes dos ditames legais que regem o Brasil.

\section{Conclusões}

Concluímos que as mulheres que denunciam os abusos, em sua maioria, procuram as instituições públicas quando já se esgotaram todas as tentativas de vivência com seu parceiro ou ex-companheiro. São mulheres carentes em termos socioeconômicos, mas, também de afeto e de apoio social. Parte significativa não completou os estudos e dependia financeiramente do agressor.

A percepção da vivência em um relacionamento agressivo, geralmente, vem após ter passado por episódios sucessivos de violências domésticas, que vão das agressões psicológicas às físicas, atingindo também as crianças da família. O medo de denunciar e a vergonha por ter sido agredida fazem parte das experiências de vida dessas mulheres. Elas 
Patrícia Rosalba Salvador Moura COSTA, José Maria Valcuende Del RÍO, Elielma Santos MACEDO, Leila Oliveira SILVA.

se culpam por aquilo de que foram vítimas. A sensação de merecimento da violência ronda as subjetividades e marca também seus corpos para o resto da vida. Chegam a questionar se ainda terão a oportunidade de serem felizes novamente.

A dependência econômica surge como um fator preponderante para a permanência no relacionamento abusivo. Mas, os aspectos emocionais e a baixa autoestima, ocasionada por agressões constantes, são pontos explicativos para as suas experiências, embora, nem sempre percebidos por elas.

Os/as profissionais da assistência social que trabalham nas cidades estudadas explanaram a gravidade do problema, com conhecimento de quem lida constantemente com casos de violências doméstica e familiar. Em uma das cidades, os equipamentos parecem funcionar de forma mais adequada por causa da política que dá sustentação as ações. $\mathrm{O}$ acesso a algumas instâncias da rede de proteção existe, mas com certo grau de dificuldade, portanto, a funcionalidade e a rapidez precisam ser ajustadas às especificidades geográfica e sociais da região. A distância que as mulheres necessitam percorrer, por exemplo, para acessar instituições necessárias à investigação dos casos e proteção das mesmas, contribui para colocá-las em um processo constante de revitimização e sofrimento. Nesses episódios, a desistência torna-se uma alternativa forte.

A ausência de uma delegacia especializada para atendimento às mulheres em situação de violências, nas cidades estudadas, ou ao menos, na região do Alto Sertão, surge como um problema que interfere diretamente na adequação do acolhimento às vítimas. A falta de estrutura e de profissionais capacitados/as para lidar com a temática pode causar mais trauma às mulheres e, de certa forma, prejudicar o encaminhamento dos casos. Por outro lado, é preciso ratificar que os crimes de violências doméstica e familiar são os mais registrados nas delegacias, isso significa que é urgente uma maior atenção do poder público para essas questões.

Por fim, cabe registrar que as violências domésticas estão ancoradas também no ciúme, na não aceitação da separação por parte dos homens, na alegação do uso drogas lícitas ou ilícitas, somados às características de uma mulher que vive em locais distantes dos grandes centros, em situação de vulnerabilidade financeira, educacional, familiar, e, por conseguinte, às fragilidades no acesso às redes de apoio. As cidades aqui estudadas ainda carecem de melhoria significativa em relação à 
situação socioeconômica de suas mulheres, principalmente, as que vivem e sobrevivem na zona rural.

\section{Referências}

BRASIL. Lei $n^{\circ}$ 11.340, de 7 de agosto de 2006. Cria mecanismos para coibir a violência doméstica e familiar contra a mulher [...]. Brasília, DF: Presidência da República. Disponível em: http://www.planalto.gov.br/ccivil_03/_ato20042006/2006/lei/l11340.htm. Acesso em: o5 dez. 2019.

BRASIL. Lei $n^{\circ}$ 13.827, de 13 de maio de 2019. Altera a Lei Maria da Penha de 2006. Brasília, DF: Presidência da República. Disponível em: http://www.planalto.gov.br/ccivil_03/_ato20192022/2019/lei/L13827.html. Acesso em: 05 dez. 2019.

BRASIL. Ministério da Saúde. Conselho Nacional de Saúde. Resolução no 510, de 7 de abril de 2016. Diário Oficial da União: Seção 1, Brasília, DF, ed. 98, p. 44, 24.05.2016. Disponível em: http://www.in.gov.br/materia//asset_publisher/KujrwoTZC2Mb/content/id/22917581. Acesso em: 02 maio 2020.

BUTLER, Judith P. Problemas de gênero: feminismo e subversão da identidade. Tradução de Renato Aguiar. Rio de Janeiro: Editora Civilização Brasileira, 2003.

CARDOSO DE OLIVEIRA, Roberto. O trabalho do antropólogo. Brasília: Paralelo Quinze; São Paulo: Editora da Unesp, 1998.

CORRÊA, Mariza. Morte em família: representações jurídicas de papéis sexuais. Rio de Janeiro: Graal, 1983.

COSTA, Patrícia R. S. M.; MARQUES, Amanda Christinne N.; OLIVEIRA, Hannah U. Direitos, todas/os têm? O coro das mulheres assentadas sobre (in)visibilidade, lutas e políticas públicas. Mulheres do campo: Identidades, Políticas Públicas e Gênero, Aracaju: Criação, v. 1, p. 27-62, 2016.

COSTA, Patrícia R. S. M.; NICHNIG, Claudia. R. Percursos Metodológicos para o Estudo de Fontes Judiciais: um debate interdisciplinar nas ciências humanas. In: OLIVEIRA, Esmael A. de; VIANA JÚNIOR, Mário M.; 
Patrícia Rosalba Salvador Moura COSTA, José Maria

Valcuende Del RÍO, Elielma Santos MACEDO, Leila

Oliveira SILVA.

COSTA, Patrícia R. S. M. (orgs.). Metodologias de pesquisa em Ciências Humanas: campos, problemas e objetos. Curitiba: CRV, v. 1, 2015. p. 4556.

CUNHA, Tânia Rocha Andrade. O preço do silêncio: mulheres ricas também sofrem violência. Vitória da Conquista: Ed UESB, 2007.

FÓRUM BRASILEIRO DE SEGURANÇA PÚBLICA. Anuário Brasileiro de Segurança Pública 2019, ano 13, 2019. Disponível em: www.forumseguranca.org.br. Acesso em: 01 abr. 2019.

GREGORI, Maria Filomena. As desventuras do vitimismo. Estudos Feministas, Rio de Janeiro, v. 1, p. 143-150, 1993 b.

GREGORI, Maria Filomena. Cenas e queixas: um estudo sobre mulheres, relações violentas e a prática feminista. Rio de Janeiro: Paz e Terra; São Paulo: APOCS, 1993a.

GREGORI, Maria Filomena. Violence and gender: Political paradoxes, conceptual shifts. Vibrant: Virtual Brazilian Anthropology, Brasília: $\mathrm{ABA}, \mathrm{v} .7$, n. 2, p. 216-235, july to december 2010. Disponível em: http://www.vibrant.org.br/issues/v7n2/maria-filomena-gregoriviolence-and-gender/ Acesso em: 03 abr. 2020.

GROSSI, M. P. De Angela Diniz a Daniela Perez: A trajetória da impunidade. Revista de Estudos Feministas, Florianópolis, n. 1, p. 166168, 1993.

GROSSI, M. P. Direitos Humanos, feminismo e lutas contra a impunidade. Antropologia em primeira mão, Florianópolis, PPGAS UFSC, p. 1-13, 1998a.

GROSSI, M. P. Gênero, violência e sofrimento. Antropologia em primeira mão, Florianópolis, PPGAS UFSC, p. 1-22, $1998 \mathrm{~b}$.

GROSSI, M. P. O significado da violência nas relações de gênero no Brasil. Sexualidade, Gênero e Sociedade, Rio de Janeiro, v. 2, n. 4, 1995.

GROSSI, M. P. Rimando amor e dor: reflexões sobre a violência no vínculo afetivo-conjugal. In: GROSSI, M. P.; PEDRO, J. Masculino e feminino, plural. Florianópolis: Mulheres, 1998c. p. 293-312. 
GROSSI, M. P. Velhas e novas violências contra a mulher: 15 Anos de lutas e estudos feministas. Revista Estudos Feministas, Florianópolis, (UFSC. Impresso), Brasil, v. esp., p. 473-484, 1994.

GROSSI, M. P.; MINELLA, L. S.; PORTO, R. Depoimentos: trinta anos de pesquisas feministas brasileiras sobre violência. Florianópolis: Editora Mulheres, 2006.

INSTITUTO DE PESQUISA ECONÔMICA APLICADA. Atlas da Violência 2019. Fórum Brasileiro de Segurança Pública, Brasília, Rio de Janeiro, São Paulo, p. 14-8, 2019.

MACHADO, Isadora Vier; GROSSI, Miriam Pillar. Historicidade das violências psicológicas no Brasil e judicialização, a partir da Lei 11.340/o6 (Lei Maria da Penha). Revista Brasileira Resumo Direitos Fundamentais \& Justiça, Belo Horizonte, ano 6, n. 21, p. 84-104, out./dez. 2012. Disponível em: http://dfj.emnuvens.com.br/dfj/article/view/292/617. Acesso em: 05 maio 2020.

MELLO, Anahi. G. Gênero nas políticas da deficiência, deficiência nas políticas para mulheres: uma análise de documentos oficiais sobre violências contra mulheres com deficiência. In: MORAES, Marcia; MARTINS, Bruno S.; FONTES, Fernando; MASCARENHAS, Luiza T. (orgs.). Deficiência em questão: para uma crise da normalidade. Rio de Janeiro: NAU, 2017. p. 163-191.

PARENT, Collete. Face à l'insoutenable de la violence contre les conjointes: les femmes como actrices sociales. In: DEBUYST, C.; DIGNEFFE, F.; KAMINSKI, D.; PARENT, C. Essais sur le tragique et la rationalité pénale. Bruxelles: Éditions De Boek Université, 2002. p. 83103.

REGO, Walquiria Leão; PINZANI, Alessandro. Vozes do Bolsa Família: autonomia, dinheiro e cidadania. São Paulo: Editora Unesp, 2013.

SADENBERG, Cecília; GROSSI, Miriam. Dossiê: balanço sobre a Lei Maria da Penha. Estudos Feministas, Florianópolis, v. 23, n. 2, p. 497500, maio-agosto. 2015 .

SADENDERG, Cecília. Políticas de enfrentamento da violência contra mulheres no Brasil: construção e desmonte. Estudios de Políticas Públicas, Santiago, v. 8, p. 78-98, 2018. 
Patrícia Rosalba Salvador Moura COSTA, José Maria

Valcuende Del RÍO, Elielma Santos MACEDO, Leila

Oliveira SILVA.

SANTOS, Cecília M.; IZUMINO, Wânia P. Violência contra as Mulheres e violência de Gênero: notas sobre estudos feministas no Brasil. Estudios Interdisciplinarios de América Latina Y El Caribe, Tel Aviv, v. 16, n. 1, 2005. Disponível

em:

http://eial.tau.ac.il/index.php/eial/article/view/482. Acesso em: 17 set. 2018.

SANTOS, Claudiene; UNGER, Lynna Gabriella. S. Ciúme, o tempero do amor? compreendendo as percepções de jovens em Aracaju/SE. In: SEMINÁRIO ENLAÇANDO SEXUALIDADES, 4., 2015, Salvador: UNEB. Anais [...]. Salvador: UNEB, 2015. v. 1. p. 1-1.

SANTOS, Rayane M.; COSTA, Patrícia R. S. M.; TRIÑANES, Giovanna. L. R.; GROSSI, Miriam P. O caso Geisy Arruda: representações midiáticas brasileiras sobre violências contra mulheres. Bagoas: Revista de Estudos Gays, Natal, v. 6, p. 1-23, 2012.

SCOTT, Joan W. Gender: A Useful Category of Historical Analysis. American Historical Review, Oxford, v. 91, n. 5, p.1053-1075, 1986.

SCOTT, Joan. O enigma da igualdade. Rev. Estud. Fem., Florianópolis, v. 13, n. 1, p. 11-30, jan./apr. 2005. Disponível em: https://www.scielo.br/scielo.php?script=sci_arttext\&pid=So104026X2005000100002. Acesso em: 05 maio 2020.

SCOTT, Parry; NASCIMENTO, Fernanda Sardelich; CORDEIRO, Roseneide; NANES, Giselle. Redes de enfrentamento da violência contra mulheres no sertão de Pernambuco. Rev. Estud. Fem., Florianópolis, v. 24, n. 3, p. 851-870, set./dez. 2016. 


\section{Domestic Violence, Experiences and Difficulties in the Northeastern Semiarid}

ABSTRACT: The article presents results on the characteristics of crimes of domestic and family violence, registered in two municipalities in the Alto Sertão of Sergipe, whose region has multiple needs, in terms of access to public policies. The data analyzed were: police inquiries; interview with women who experienced episodes of violence and social assistance and law professionals. The results focus on the experiences and difficulties faced by women victims of domestic violence, as well as the problems experienced by the professionals who must put into practice the defense of the victims' rights in a territory far from the large centers.

Keywords: Violence. Women. Semi-arid of Sergipe. Public Policy.

\section{Patrícia Rosalba Salvador Moura COSTA}

Professora doutora do Campus do Sertão e do Mestrado em Antropologia da Universidade Federal de Sergipe. Desenvolve pesquisas na área interdisciplinar em Humanidades, com ênfase para os campos gênero e ruralidades, relações de poder, violências, sexualidades . Líder e pesquisadora do grupo de pesquisa XiqueXique UFS/CNPq (Grupo de Pesquisa Gênero e Sexualidade).

Universidade Federal de Sergipe Email: patriciarosalba@gmail.com

\section{José Maria Valcuende Del Río}

Professor Doutor do Departamento de Antropologia Social, Psicologia Básica y Saúde Pública da Universidade Pablo de Olavide, Espanha. Coordenador do Laboratório Iberoamericano para el estúdio sociohistorico de la sexualidades- Red LIESS Universidad Pablo de Olavide

Email:jmvalrio@upo.es 
Elielma Santos MACEDO

Graduanda em Bacharelado em Agroindústria. Aluna bolsista de Iniciação Científica/CNPq/UFS Universidade Federal de Sergipe Email: elielma.pjr@hotmail.com

\section{Leila Oliveira SILVA}

Estudante do curso de Letras Inglês da Universidade Federal de Sergipe. Bolsista voluntária do Programa de Inciação Científica/CNPq/UFS

Universidade Federal de Sergipe Email: agro.leila@outlook.com

Recebido em: 27/o9/2020

Aprovado em: 27/o1/2021 